Ferenc Postma

\title{
Ex libris Steph. S. Mányoki
}

\author{
Zeldzaam academisch drukwerk uit Franeker in de Klimo \\ Bibliotheek te Pécs
}

\begin{abstract}
Some years ago, we discovered a Dutch item in the famous Klimo Library at Pécs. It is a Convolute, composed of 67 booklets, all printed in the Netherlands in the first half of the 17th century. The collection was made by a Hungarian student of theology from Debrecen, Stephanus / István S. Mányoki, during his stay as a peregrinus in the Netherlands, where he studied at the protestant universities in Groningen, Franeker, Leiden and Utrecht respectively (1646-1648). Later on, this collection of academic imprints came into the possession of Matthias / Mátyás Domsics (1691-1768), a Canon of the Cathedral at Pécs, in order to be used for his Refutation of the Protestant Doctrine of the Faith. However, Domsics could not finish his dogmatic studies. In 1767, the new Roman Catholic bishop of Pécs, Georgius / György Klimo (1710-1777), took over all the books Domsics had collected for that purpose. Thus, Mányoki's Convolute of Dutch protestant academic imprints became a part of bishop Klimo's library.

Mányoki's Convolute makes a valuable contribution to current Dutch research in book history. This Convolute will be a great enrichment, especially for the "Short-Title Catalogue Netherlands" (STCN).

Keywords: Stephanus / István S. Mányoki; Peregrinatio hungarica; Franeker University; Klimo Library at Pécs; Bibliographical research; Book History
\end{abstract}

Zoals bekend, leidde de intocht in de Noordelijke Nederlanden van de vele protestantse studenten uit (het historische) Hongarije - in de vroegmoderne tijd - tot een uittocht van een welhaast ontelbare hoeveelheid boeken en geschriften uit de Republiek. ${ }^{1}$ Niet alleen brachten deze Peregrini die gedrukte geschriften mee terug naar huis die ze zelf aan de 
(verschillende) universiteiten hadden geschreven, ofwel verdedigd (oefendisputaties, dissertaties, carmina, klassieke en theologische commentaren, exegetische, filologische en historische studies, vertalingen, etc.), maar ook talloze andere boeken die ze van hun medestudenten, hun professoren, en van wie ook maar ten geschenke hadden gekregen - bijv. van kerkenraden en predikanten, die hen op hun studiereis hier ten lande met meer dan alleen geldelijke middelen ondersteunden. Natuurlijk kochten ze ook zelf boeken in de reguliere boekwinkels, naarmate hun financiële budget dat toeliet, ${ }^{2}$ de een dus beduidend meer dan de ander. ${ }^{3}$ Zo landden successievelijk duizenden boeken en geschriften in het Hongaarse achterland, waar ze ten laatste een plaats vonden in vele bibliotheken en archieven. Dat zich daaronder ook talloze drukken bevinden die heden ten dage niet meer in Nederland, of beter, niet meer in de Nederlandse bibliotheken te vinden zijn, behoeft hier nauwelijks verder betoog. Zo biedt (het historische) Hongarije - waarbij vooral ook te denken valt aan Zevenburgen / Transsylvanië (nu deel van Roemenië) - een ongekende schat aan zeldzaam drukwerk uit de toenmalige Nederlanden. ${ }^{4}$ Maar al te vaak gaat het daarbij om "unieke" exemplaren, d.w.z. om boeken die tot nu toe nergens anders werden aangetroffen. Hier liggen dus - kort gezegd - ongekende kansen en mogelijkheden voor het huidige Nederlandse boekhistorisch onderzoek. De Short-Title Catalogue Netherlands (STCN) zou hierdoor tegelijk - qua bestand en inhoud - in belangrijke mate verrijkt kunnen worden.

Van alle - vijf - universiteiten in de Republiek was de Friese universiteit te Franeker bij de Hongaarse Peregrini bijzonder geliefd. ${ }^{5}$ Deze universiteit had - kort nadat de Reformatie in Friesland officieel vaste voet had gekregen - op 29 juli 1585 zijn deuren plechtig geopend ${ }^{6}$ - sindsdien gevestigd in het voormalige Kruisherenklooster. Met name na de val van Heidelberg (tijdens de 30-jarige oorlog, begin september 1622) werd de Franeker universiteit voor de Hongaarse studenten hun echte Alma Mater, zoals Heidelberg dat voor die tijd geweest was, en bleef dat tot het jaar 1811 , toen de deuren van de universiteit op gezag van Napoleon, de Franse keizer en toenmalige heerser over de Nederlanden, definitief werden gesloten. Gedurende al die tijd hebben meer dan 1.200 Peregrini hun weg naar het verre Franeker weten te vinden, ${ }^{8}$ nog afgezien van alle individuele Hongaarse "bezoekers". ${ }^{9}$ Wat het aantal Hongaarse Peregrini betreft, spant de Friese universiteit dus absoluut de kroon, vergeleken met hun numerieke aanwezigheid destijds aan de andere universiteiten in de Republiek. De 
meesten van hen studeerden er filosofie, theologie en/of medicijnen, op academisch niveau - iets wat in hun eigen vaderland niet mogelijk was.

Dat onder het vele drukwerk uit de toenmalige Nederlanden indertijd ook talloze academische drukken uit Franeker hun weg hebben gevonden naar het Hongaarse achterland, is zonder meer duidelijk. Zo treffen we bijvoorbeeld vandaag de dag een achttal Franeker oefendisputaties aan in de rijke bestanden van de Universiteitsbibliotheek in Pécs, om precies te zijn in de Klimo Bibliotheek (zie beneden de Franeker Bibliografie). Alle acht zijn het zeldzame exemplaren, onderdelen van een omvangrijke convoluut, ${ }^{10}$ waarin - in totaal - maar liefst 67 academische drukken uit de Nederlanden zijn bijeengebonden. Het gros stamt uit de jaren 1642-1648, en betreft theologisch drukwerk dat - afgezien van in Franeker - in Deventer, Groningen, Utrecht en Leiden werd gedrukt (zie beneden de Bijlage), kortom een ware "Fundgrube" voor de STCN. In diezelfde jaren zal deze bundel "Disputationes theologicae" wij aannemen door de Hongaarse Peregrinus Stephanus / István S. Mányoki, een theologiestudent afkomstig uit Debrecen, ${ }^{12}$ wiens naam daarin op vele plaatsen opduikt, niet alleen in gedrukte vorm (resp. de Volgnummers 36 en 60, zie de Bijlage), maar ook in handschrift. Bijna een eeuw later - tijdens de lange regeringsperiode van Maria Theresia (17401780) ${ }^{13}$ - raakt Mányoki's bundel Protestantica dan in rooms-katholieke handen, wanneer het convoluut in het bezit komt van Matthias / Mátyás Domsics (1691-1768), "canonicus" van de grote kathedraal in Pécs, die sinds medio februari 1746 - in opdracht van zijn bisschop Sigismundus / Zsigmond Berényi - de publicatie van een fundamentele, systematischtheologische weerlegging van iedere vorm van heterodoxie voorbereidde, ${ }^{14}$ en in het kader daarvan volijverig vele "heterodoxe" (lees vooral: protestantse) werken, ${ }^{15}$ ja zelfs kerkelijk-verboden boeken verzamelde. Langer dan twintig jaar werkte Domsics aan deze kerkelijke opdracht, maar kennelijk zonder vruchtbaar resultaat, waarop de nieuwe bisschop van Pécs, Georgius / György Klimo (1710-1777), ${ }^{16}$ in juli 1767 beslag laat leggen op diens boeken en deze onderbrengt in zijn eigen, bisschoppelijke bibliotheek. Hoeveel boeken Domsics in al die jaren wel niet verzameld had, wordt duidelijk uit de werkelijk indrukwekkende - handgeschreven inventarislijst van zijn boekenbezit, ${ }^{17}$ die daarbij werd opgesteld: "Catalogus Librorum Haeterodoxorum Reverendissimi Domini Mathiae Domsics, Cathedralis Ecclesiae Quinque Ecclesiensis Custodis, et Canonici". ${ }^{18}$ Daarin treffen we - op fol. 224, als nummer 73 - ook Má- 
nyoki's bundel Protestantica aan, eenvoudigweg beschreven conform de titel van de allereerste oefendisputatie in het omvangrijke convoluut:

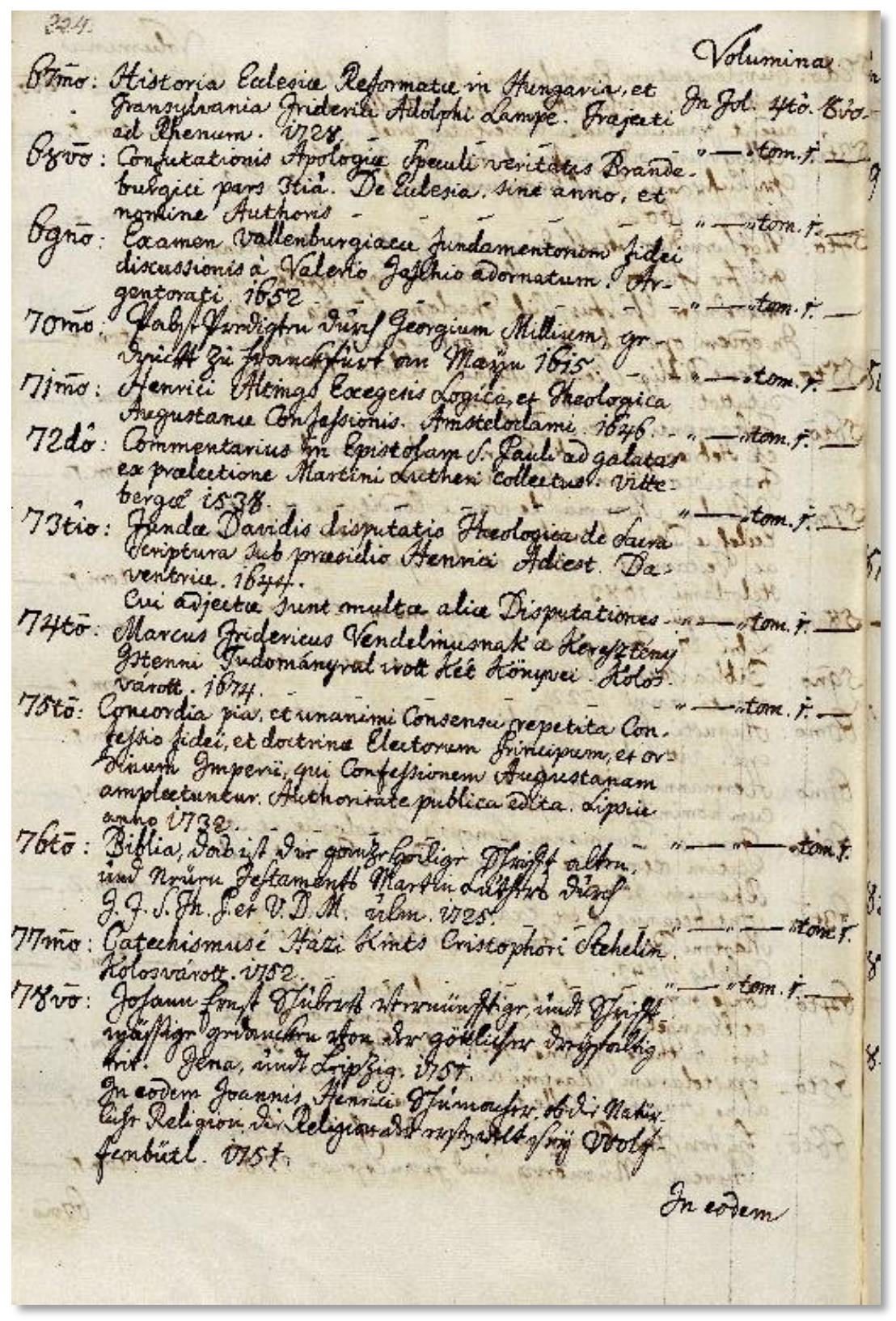

Catalogus Domsics, fol. 224, nr. 73: Convoluut van Mányoki. 
73. Fundae Davidis disputatio theologica de Sacra

Scriptura sub praesidio Henrici Adiest. Daventriae 1644.

Cui adjectae sunt multae aliae Disputationes.

Tegelijk vermeldt het titelblad van deze eerste theologische oefendisputatie "De Sacra Scriptura" - op de 26e oktober 1644 verdedigd door de Hongaarse Peregrinus Nicolaus / Miklós Szoboszlai onder leiding van de Deventer hoogleraar Henricus a Diest (of ook: Henricus Diestius, 1595$1673)^{19}$ - het handgeschreven "Ex libris" van onze Stephanus / István S. Mányoki, die we reeds boven noemden. Een interessant gegeven, omdat Mányoki - voor zover wij weten - zelf niet in Deventer had gestudeerd, maar pas later, op 22 september 1646, student zou worden in Groningen. ${ }^{20}$ Mogelijk heeft hij de disputatie ten geschenke gekregen van zijn land- en studiegenoot Nicolaus / Miklós Margitai, ${ }^{21}$ wiens naam we wel in het Deventer Album Studiosorum aantreffen. ${ }^{22}$ Hoe het ook zij, het typeert Mányoki direct als een verzamelaar van academisch drukwerk - zelfs uit de tijd ver voor zijn verblijf in de Republiek. Daarmee doelen we concreet op de twee theologische oefendisputaties uit respectievelijk 1625 en 1626, die toentertijd onder leiding van de hoogleraar Gulielmus Amesius $(1576-1633)^{23}$ in Franeker waren verdedigd (resp. de Volgnummers 37 en 42, zie de Franeker Bibliografie). Mányoki zal beide zeldzame disputaties stellig in Franeker zelf in handen hebben gekregen, waar hij zich na zijn verblijf in Groningen op 27 januari 1647 als student had laten inschrijven. ${ }^{24}$ Hetzelfde geldt ook voor de overige Franeker oefendisputaties in zijn omvangrijke convoluut, die alle zes uit respectievelijk 1646 en 1647 stammen (resp. de Volgnummers 28-32 en 39, zie de Franeker Bibliografie) en - op de Poolse student Stanislaus Hermannus na ${ }^{25}$ - in de kring van zijn eigen Hongaarse studiegenoten onder leiding van de hoogleraar Johannes Cloppenburg (1592-1652) zijn verdedigd. Van Cloppenburg weten we, hoezeer hij de Hongaarse Peregrini - niet alleen op zijn hooren dispuutcolleges, maar ook bij hem thuis, door middel van privatissima - heeft betrokken bij zijn grondige weerlegging van de "leere der Socinianen", ${ }^{26}$ om hen zo voor hun toekomstige taak - de "verdediging van het Hongaarse Sion" - toe te rusten. Reeds in 1646 makkte hij daarmee een begin, ${ }^{27}$ door de systematische weerlegging ("elenchus") van een anti-trinitarisch geschrift - "De divinitate Jesu Christi" (verschenen: Racoviae / Raków, 1608) - van de Sociniaan Valentinus Smalcius (15721622). 


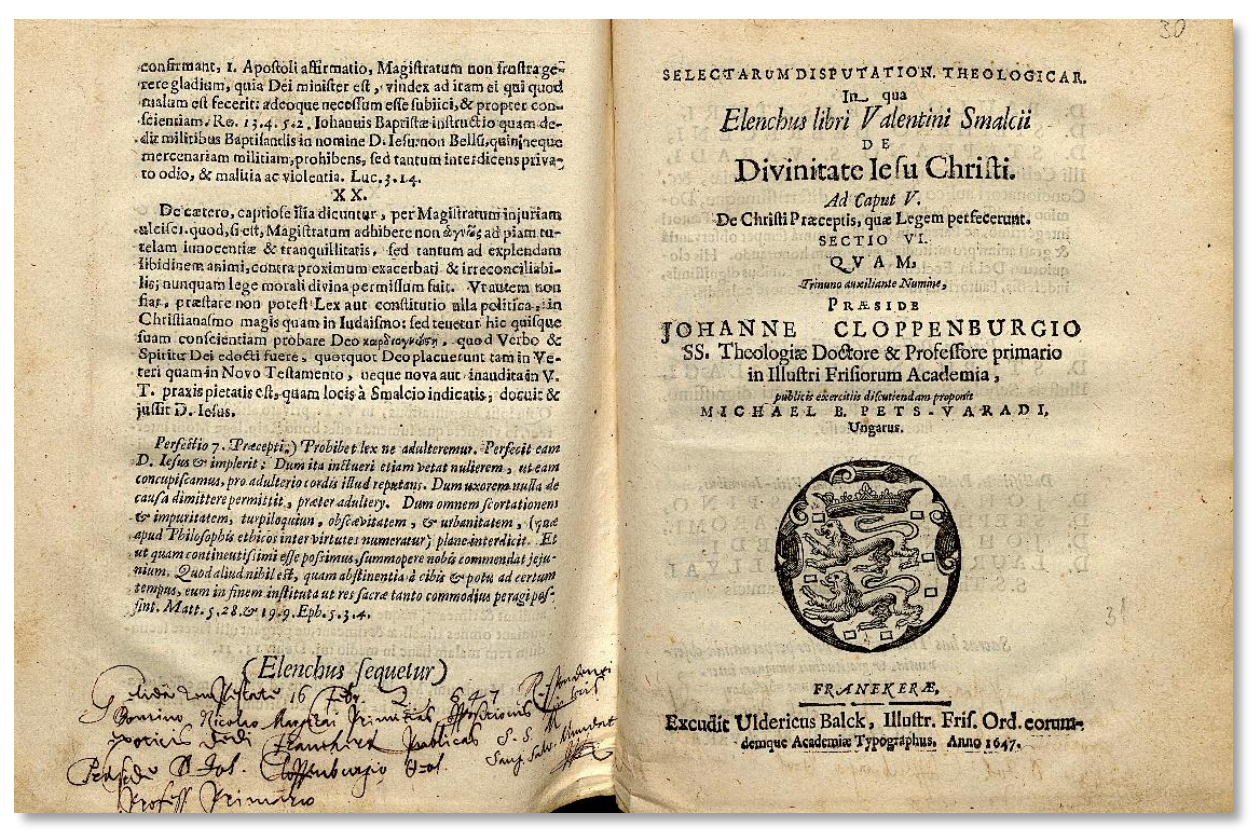

De notitie van Mányoki aan het slot van de oefendisputatie van Margitai, met de titelpagina van de oefendisputatie van Pets-Varadi (1647).

In een reeks van niet minder dan veertig oefendisputaties zou hij zijn studenten tegen Smalcius' theologische opvattingen laten disputeren, om drie jaar later - in 1649 - het eerste deel van zijn "Anti-Smalcius" in Franeker te publiceren. ${ }^{28}$ In de lange naamlijst van alle vijfentwintig studenten die daarbij betrokken waren, komen we evenwel de naam van onze Mányoki niet tegen. Wel treffen we daarin de namen aan van zijn directe studiegenoten: Johannes Crispinus, ${ }^{29}$ Nicolaus Margitai, Michael B. PetsVaradi, ${ }^{30}$ Stephanus A[nderko] Szokolyai ${ }^{31}$ en Stephanus Peeri, ${ }^{32}$ van wie we nu dus ook - als vrucht van zijn noeste verzamelarbeid - over hun oorspronkelijke oefendisputaties uit deze reeks beschikken - concreet: De nummers XIII, XVII, XVIII, XIX en XX, uit respectievelijk 1646 en 1647. Dat Mányoki daarentegen wel degelijk bij dit alles zelf betrokken is geweest, bewijzen de aantekeningen die hij in elk van deze vijf exemplaren maakte. Zo lezen we bijvoorbeeld, dat hij op 16 februari 1647 - "bij ijzige koude" 33 - voor het eerst "in den vreemde" 34 als "Opponens" was opgetreden in Franeker bij het publieke dispuut van Nicolaus Margitai (Volgnummer 29). En dat hij enkele weken later - op de 6e maart 1647 eveneens "Opponens" geweest was bij het dispuut van Stephanus A. 
Szokolyai, en wel tezamen met Johannes Crispinus (Volgnummer 31). ${ }^{35}$ Uit andere bronnen weten we, dat hij Franeker kort daarop zou verlaten, om zich - samen met Peeri en Szokolyai - op 25 maart 1647 als student te laten inschrijven in Leiden. ${ }^{36}$ Dat hij zich naderhand ook nog in Utrecht moet hebben opgehouden, valt met zekerheid af te leiden uit de vele Utrechtse oefendisputaties ${ }^{37}$ - alle verdedigd onder leiding van de hoogleraar Gisbertus Voetius (1589-1676) - die we in zijn omvangrijke convoluut ingebonden vinden. Wellicht heeft hij de hele bundel daar ook samengesteld en in een eenvoudige band - als kwartijn - laten inbinden: Dezelfde perkamenten band, die - hoezeer ook in de loop der tijd gehavend en versleten - ook nog vandaag de dag de bundel siert.

Zoals bekend, keerde Mányoki in de loop van 1648 terug naar Debrecen, waar hij eind december van dat jaar ${ }^{38}$ als professor verbonden werd aan het illustre protestantse Collegium, waar hij destijds ook zijn studie was begonnen. Veel meer dan dat hij daar een jaar later - in 1649 als rector zou optreden, ${ }^{39}$ weten we echter niet. Mogelijk is hij daar ook gestorven en wel in 1685. Een handgeschreven notitie op de binnenzijde van de band van het convoluut maakt immers duidelijk, dat zijn bundel "Disputationes theologicae" in dat jaar van eigenaar is gewisseld: "Possidet And. S. Pathai / Debrecini 1685. 6. / 8bris". In october 1688 werd vervolgens een zekere Johannes/ János Erdélyi de rechtmatige bezitter, ${ }^{40}$ waarna Mányoki's omvangrijke bundel Protestantica meer dan een halve eeuw later - zoals we gezien hebben - terecht komt in Pécs.

Daar kreeg het convoluut - hoe "heterodox" ook qua inhoud - uiteindelijk een plaats in de grote bibliotheek van bisschop Klimo - waardoor het bewaard is gebleven, en ook vandaag de dag nog een "Fundgrube" is voor verder boek- en cultuurhistorisch onderzoek. 


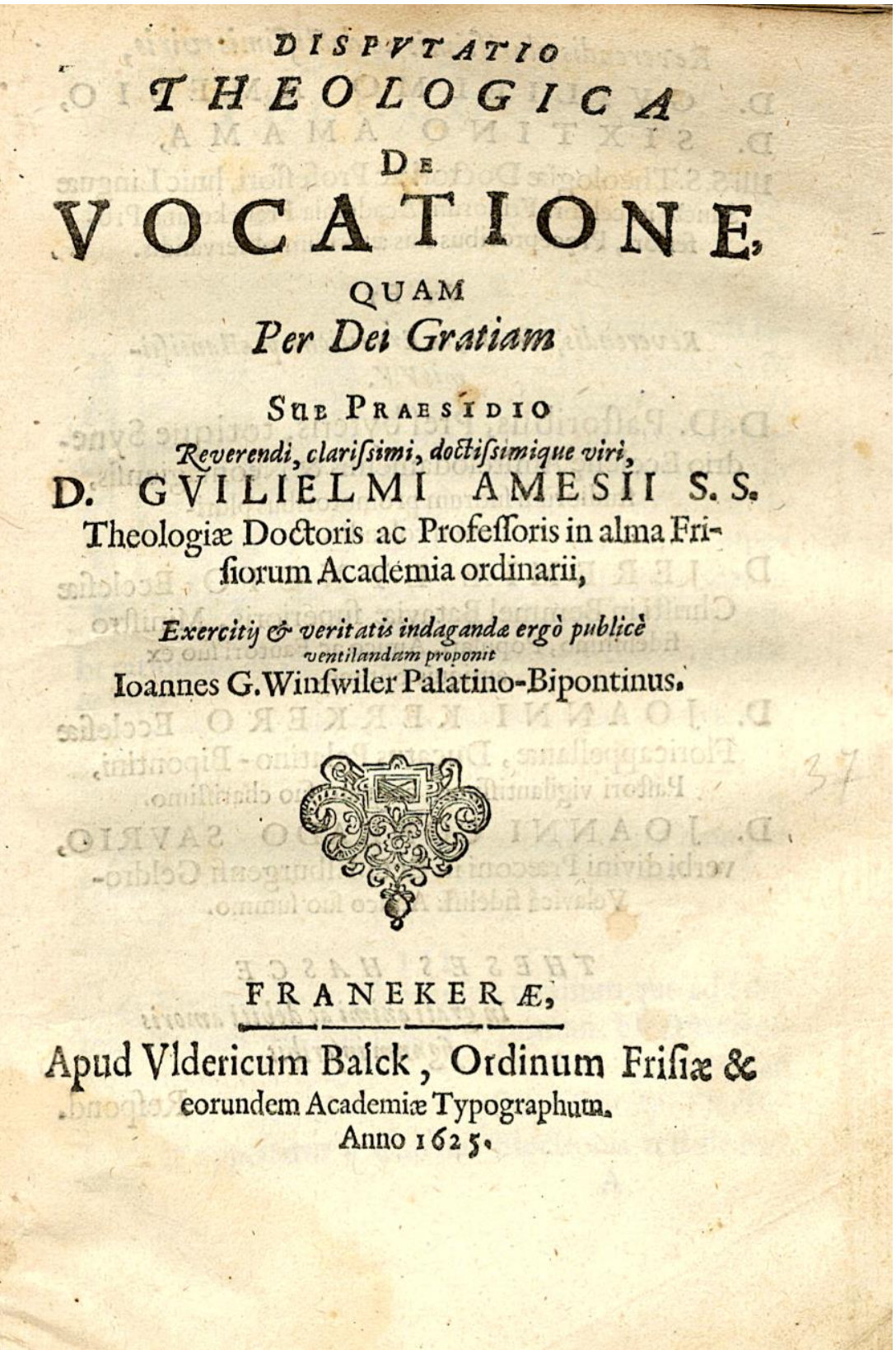

De oefendisputatie van Joannes G. Winswiler sub Amesius (1625). 


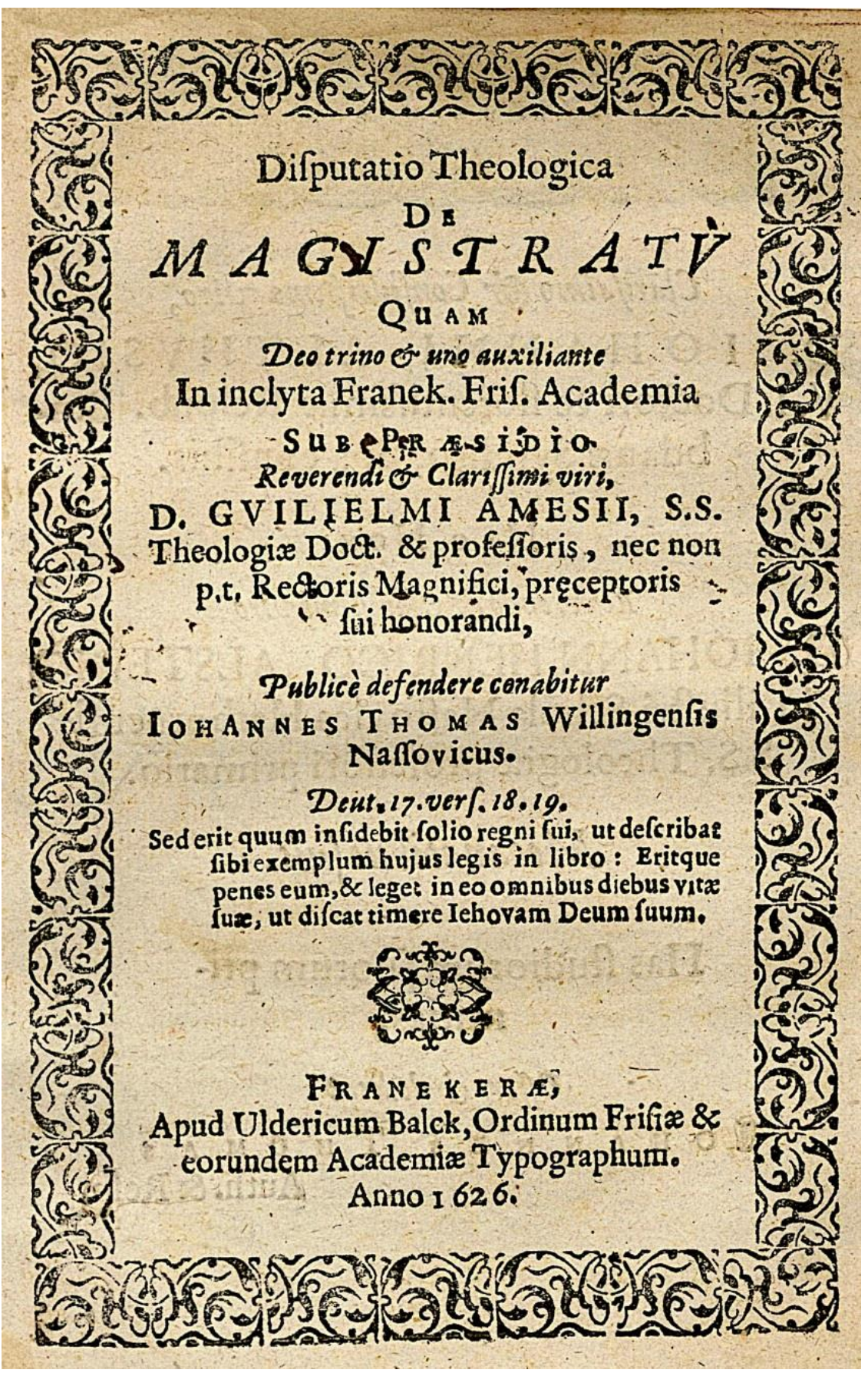

De oefendisputatie van Johannes Thomas sub Amesius (1626). 


\section{FRANEKER BIBLOGRAFIE}

Evenals in ons Auditorium Academiae Franekerensis (1995) bepalen de professoren, als Praesides van de onder hun leiding verdedigde oefendisputaties (Disputationes exercitii gratia), de volgorde van de hieronder vermelde titels. Van een chronologische volgorde is dus geen sprake.

- De professoren zijn alle van een nummer voorzien conform het jaar van hun aantreden als hoogleraar in Franeker. Tegelijk zijn hun vakgebied(en) resp. faculteit(en) en de jaren van hun werkzaamheid in Franeker aangegeven.

- Deze recent gevonden titels konden helaas niet in chronologische volgorde aan ons Auditorium Academiae Franekerensis worden toegevoegd, maar uitsluitend in numerieke zin.

- De titels van de incomplete Disputationes exercitii gratia (i) onder leiding van professor Johannes Cloppenburg (56/1646.6; 56/1647.2; $56 / 1647.5)$ werden nader samengesteld, dan wel gereconstrueerd, aan de hand van handgeschreven aantekeningen in de beide - in Alba Iulia en Pécs - bewaard gebleven exemplaren.

- Voor de hier en elders gebezigde afkortingen, zie: Bibliografie.

\section{6/ Gulielmus AMESIUS, theologia 1622-1633}

36/1625.4 Disputatio theologica de vocatione. [Resp.] Joannes G[eorgius] Winswiler, Palatino-Bipontinus. Franekerae, Uldericus Balck, 1625. 4to; [12] pp.

Carmina: Paulus Puah Miskolczi (lat.); Andreas Rotarius A.F. (lat.). Loc.: Pécs $<$ DD VI.12 (37) $>$; Cluj $<$ R RMK 606/m $>-A S t F$, Nr. 2062. Niet in RMKP. - Móró 2001, p. 21 (Nr. A 258). ${ }^{41}$

36/1626.8 Disputatio theologica de magistratu. [Resp.] Johannes Thomas, Willingensis Nassovicus. Franekerae, Uldericus Balck, 1626. 4to; [16] pp.

Carmina: Henricus Britman (Lat.); Sebastianus Pfochenius (Grieks). Loc.: Pécs <DD VI.12 (42)> - AStF, Nr. 2344. - De student Johannes Thomas was ook de "Auth[or]" van deze Disputatio (A verso). - Aan het einde: "Corollaria" (I-III). - N.B.: Deze Disputatio werd tijdens het 
rectoraat van Amesius verdedigd (Titelpagina). - Móró 2001, p. 21 (Nr. A 257). ${ }^{42}$

\section{0/ Johannes COCCEJUS, artes 1636-1650 \& theologia 1643- 1650}

50/1647.1 Dissertatio theologica de legitima ministrorum ecclesiae reformatae vocatione. [Resp.] Stanislaus Hermannus, Polonus, ad 10 Mart. Franekerae, excudit Uldericus Balck, 1647. 4to; [24] pp.

Carmina: Praeses [= Joh. Coccejus] (lat.); Christianus Schotanus (lat.). Loc.: Pécs <DD VI.12 (39)>; Iul <E2 VIII.9 (37) ¿, [16] pp. > - AStF, Nr. 4420. - De Poolse student Stanislaus Hermannus was ook de "Author" van deze Dissertatio (A verso). - Aan het einde: "Corollaria" (I-II). Móró 2001, p. 138 (Nr. C 512). - N.B.: Zie voor een afbeelding van het titelblad: Postma, Nihil sine litteris, 597.

* Het exemplaar in Alba Iulia is incompleet $(i)$.

\section{6/ Johannes CLOPPENBURG, theologia 1644-1652}

56/1646.6 [Selectarum disputationum theologicarum XIII, in qua elenchus libri Valentini Smalcii de divinitate Jesu Christi, ad capitis IV sectionem III, an homo mortalis possit aliquo modo Deum videre]. [Resp.] Johannes Crispinus, [O. Moravus], [mense Oct. 1646]. [Franekerae, excudit Uldericus Balck, 1646]. 4to; [...] pp.

Loc.: Pécs <DD VI.12 (28) ¿, [8] pp.>; Iul <E2 VIII.9 (34b) ¿, [8] pp.> $A S t F$, Nr. 4151. - Móró 2001, p. 137 (Nr. C 499). - Cf. Auditorium: 56/1649.1;13 resp. 56/1652.2;13.

* Beide exemplaren, in Alba Iulia en Pécs, zijn incompleet (¿). Zij hebben geen eigen titelpagina.

* Hs.- aantekening van Stephanus S. Mányoki in ex. Pécs (A4 verso): "Franekerae disputatae a D. Johan. Crispino, Alumno Albensi".

56/1647.2 [Selectarum disputationum theologicarum XVII, in qua elenchus libri Valentini Smalcii de divinitate Jesu Christi, ad caput V de Christi praeceptis, quae legem perfecerunt, sectio V]. [Resp.] Nicolaus Margitai, [Ungarus], [16 Febr. 1647]. [Franekerae, excudit Uldericus Balck, 1647]. 4to; [...] pp. 
Loc.: Pécs <DD VI.12 (29) ¿, [8] pp.>; Iul <E2 VIII.9 (34c) ¿, [8] pp. > $A S t F$, Nr. 4363. - Cf. RMKP 6317. - Móró 2001, p. 137 (Nr. C 500). Cf. Auditorium: 56/1649.1;17 resp. 56/ 1652.2;17.

* Beide exemplaren, in Alba Iulia en Pécs, zijn incompleet (¿). Zij hebben geen eigen titelpagina.

* Hs.- aantekening van Stephanus S. Mányoki in ex. Pécs (A4 verso):

"Gelida tempestate 16 Febr. A. 1647 Respondenti / Domino Nicolao Margitai primitias oppositionis in locis / exoticis dedi Franekerae publicas / Praeside D. Joh. Cloppenburgio Theol. / Profess. Primario / S. S. M. [= Stephanus S. Mányoki] / Sang[uinem] Salv[atoris] Memento / M.pr.”.

56/1647.3 Selectarum disputation. theologicar. [XVIII], in qua elenchus libri Valentini Smalcii de divinitate Jesu Christi, ad caput V de Christi praeceptis, quae legem perfecerunt, sectio VI. [Resp.] Michael B. PetsVaradi, Ungarus. Franekerae, excudit Uldericus Balck, 1647. 4to; [12] pp. Loc.: Pécs $<$ DD VI.12 (30)>; Iul <E2 VIII.9 (35)> - AStF, Nr. 4364. RMKP 6273. - Aan het einde: "Corollaria Respondentis". - Móró 2001, p. 137 (Nr. C 501). - Cf. Auditorium: 56/1649.1;18 resp. 56/1652.2;18.

* Hs.- aantekening van Stephanus S. Mányoki in ex. Pécs (A4 verso): "Franekerae R[esp.] D. Michaele P. Pecsvaradi, [...] Varadi An. 1647”.

56/1647.4 Selectarum disputation. theologicar. XIX, in qua elenchus libri Valentini Smalcii de divinitate Jesu Christi, ad caput VI de Christi praeceptis singularibus, sectio I. [Resp.] Stephanus A. Szokolyai, Ungarus, ad 6 Mart. Franekerae, excudit Uldericus Balck, 1647. 4to; [12] pp.

Carmina: Johannes Crispinus (lat.); Steph. S. Mányoki (lat.).

Loc.: Pécs $<$ DD VI.12 (31)>; Iul <E2 VIII.9 (36a) $>-A S t F$, Nr. 4485. RMKP 6275. - Aan het einde: "Corollaria Respondentis". - Móró 2001, p. 137 (Nr. C 502). - Cf. Auditorium: 56/1649.1;19 resp. 56/1652.2;19.

* Hs.- aantekening van Stephanus S. Mányoki aan het einde, onder de twee Carmina [p. 12], in ex. Pécs: "Opponentibus nobis duobus" [= "Wij beide, Johannes Crispinus en Stephanus S. Mányoki, waren de twee opponenten bij deze disputatie van Szokolyai"].

56/1647.5 [Selectarum disputationum theologicarum XX, in qua elenchus libri Valentini Smalcii de divinitate Jesu Christi, ad caput VI de praeceptis Christi singularibus, sectio II]. [Resp.] Stephanus Peeri, 
[Ungarus], [die 10 Mart. 1647]. [Franekerae, excudit Uldericus Balck, 1647]. 4to; [...] pp.

Carmen: Johannes Crispinus (lat.).

Loc.: Pécs <DD VI.12 (32) ¿, [8] pp.>; Iul <E2 VIII.9 (36b) ¿, [8] pp.> AStF, Nr. 4482. - RMKP 6274. - Móró 2001, p. 137 (Nr. C 503). - Cf. Auditorium: 56/1649.1;20 resp. 56/1652.2;20.

* Beide exemplaren, in Alba Iulia en Pécs, zijn incompleet (i). Zij hebben geen eigen titelpagina.

* Hs.- aantekening van Stephanus S. Mányoki in ex. Pécs (V recto): "R[esp.] D. Steph. Peeri ad 10 Mart. 1647”.

\section{REGISTER van NAMEN}

Britman, Henricus - 36/1626.8

Coccejus, Johannes - 50/1647.1

Crispinus, Johannes - 56/1646.6; 56/1647.4; 56/1647.5

Hermannus, Stanislaus - 50/1647.1

Mányoki, Steph[anus] S. - 56/1647.4, cf. 56/1646.6; 56/1647.2-3;

$56 / 1647.5$

Margitai, Nicolaus [M.] - 56/1647.2

Miskolczi/ Miskolci, Paulus Puah - 36/1625.4

Peeri/ Péri, Stephanus [T.] - 56/1647.5

Pets-Varadi/ Pécsváradi, Michael B. - 56/1647.3

Pfochenius, Sebastianus - 36/1626.8

Rotarius, Andreas A.F. - 36/1625.4

Schotanus, Christianus - 50/1647.1

Szokolyai, Stephanus A[nderko] - 56/1647.4

Thomas, Johannes - 36/1626.8

Winswiler, Joannes G[eorgius] - 36/1625.4

\section{BIBLIOTHEKEN}

Cluj

Iul

Pécs
Academia România, Filiala Cluj, Biblioteca, ClujNapoca/ Kolozsvár (RO)

Biblioteca documentara "Batthyaneum", Alba Iulia/ Gyulafehérvár (RO)

Pécsi Egyetemi Könyvtár/ Klimo Könyvtár, Pécs (H) 


\section{BIJLAGE}

$\mathrm{Al}$ de andere (59) disputaties uit de Nederlanden in hetzelfde convoluut <DD.VI.12>.

* Ordening (alfabetisch): Conform de gedrukte Catalogus van Móró (2001).

* Tussen (..): Het desbetreffende Volgnummer in het convoluut zelf.

* Voor de komplete titelbeschrijvingen: Zie de gedrukte Catalogus van Móró.

* Titels (16) die in $R M K$ (resp. $R M K P$ ) vermeld worden, zijn aangegeven.

* Titels (10) die reeds in de STCN worden vermeld, zijn aangegeven.

Plaats van publicatie: DEVENTER <jaar van publicatie 1644>

Praeses/ Prof.: Henricus a DIEST, ofwel Henricus DIESTIUS (15951673):

1644: D 201 (01) = RMK III.6243. - Nicolaus SZOBOSZLAI.

* Hs.- aantekening: "Ex libris Steph. S. Manyoki ...".

1644: D 202 (02) = RMK III.6244. - Andreas WACI.

Plaats van publicatie: LEIDEN <jaren van publicatie 1643-1644>

Praeses/ Prof.: Johannes POLYANDER a KERCKHOVEN (15681646):

1644: K 127 (21) - Johannes MESSU, De divina praedestinatione.

1643: K 128 (17) - Jacobus HEYBLOCIUS, De mundi visibilis creatione.

1644: K 129 (48) - Jacobus BASELIUS, De Anti-Christo variisque ejus praecursoribus.

Plaats van publicatie: LEIDEN < jaar van publicatie 1648>

Praeses/ Prof.: Constantinus L'EMPEREUR (1591-1648):

1648: L 276 (40) = RMK III.1708. - Stephanus A. SZOKOLAEUS.

1648: L 277 (41) = RMK III.1709. - Stephanus A. SZOKOLAEUS.

1648: L 278 (36) = RMK III.6286. - Stephanus S. MANYOKINUS. 
Plaats van publicatie: GRONINGEN <jaren van publicatie 1646-1648> Praeses/ Prof.: Samuel MARESIUS (1599-1673):

1646: M 366 (52) - Petrus BAUMANNUS, De calice eucharistico. - STCN.

1648: M 367 (38) - Hermannus VOLTELEN, De bonis operibus. - STCN.

1646: M 368 (20) - Matthias VECHNERUS, De peccato originali posterior. - STCN.

1646: M 369 (19) - Johannes RAPPARDUS, De peccato originali prior. - STCN.

1648: M 370 (15) - S. MARESIUS, Quaestionum aliquot decisio academica. - STCN.

* Hs.- aantekening: "D[omi]no Steph. Many[oki]".

Plaats van publicatie: LEIDEN <jaren van publicatie 1647-1648> Praeses/ Prof.: Jacobus REVIUS (1586-1658):

1647: R 339 (18) - Antonius DANBURGH, De mundi aeternitate altera.

1647: R 340 (22) - Franciscus BURMANNUS, Super praedestinationis objecto. III.

1648: R 341 (23) - Franciscus BURMANNUS, Super praedestinationis objecto. IV.

1648: R 342 (24) - Franciscus BURMANNUS, Super praedestinationis objecto. V.

Plaats van publicatie: LEIDEN <jaren van publicatie 1646-1648> Praeses/ Prof.: Fridericus SPANHEIM (1600-1649):

1646: S 917 (34) - Godofridus SCHACHMANNUS, De C positionibus theologicis. 1647: S 918 (35) = RMK III.6277. - Johannes BELINYESINUS.

1648: S 919 (47) - Samuel HERZOGUS, De falsa ecclesia.

1648: S 920 (49) - Johannes Rodolphus HYBNERUS, De Antichristo. XXVIII.

1648: S 921 (50) - Johannes RUEFFIUS, De Antichristo. XXIX.

Plaats van publicatie: LEIDEN <jaren van publicatie 1645-1648> Praeses/ Prof.: Jacobus TRIGLAND (1583-1654):

1645: T 386 (51) = RMK III.1656. - Andreas WÁCI.

1647: T 387 (46) - Laurentius KAVAEUS, De libero hominis arbitrio.

1647: T 388 (26) - Aegidius KELLENAER, Disputatio theologica miscella.

1647: T 389 (53) - Petrus PLANCIUS, De causa impulsiva pietatis. - STCN.

1647: T 390 (54) - Nicolaus FENACOLIUS, De lege ut perfecta norma.

1647: T 391 (55) - Martinus FENACOLIUS, De adoratione Christi.

1647: T 392 (56) - Jacobus van NIEBERGEN, De precatione et gratiarum actione.

1647: T 393 (57) - Petrus KINTHIUS, De sensu Orationis dominicae.

1648: T 394 (58) - Everhardus SCHUYLIUS, De precatione religiosa.

1648: T 395 (59) = RMK III.6287. - Stephanus T. PEERI.

1648: T $396(60)=R M K$ III.1705. - Stephanus S. MANYOKINUS.

1648: T 397 (61) = RMK III.6288. - Stephanus A. SZOKOLAEUS. - STCN.

1648: T 398 (62) - Conradus SCHOONHOVE, De ecclesia Jesu Christi. LX.

1648: T 399 (63) - Philippus GEELKERKIUS, De ecclesia Jesu Christi. LXII. 
1648: T 400 (64) = RMK III.6285. - Franciscus K. FOGARASI.

1648: T 401 (65) = RMK III.1707. - Stephanus B. NOGRÁDI.

1648: T 402 (66) - Antonius DANBURGH, De sacramentis.

1646: T 403 (45) - Petrus WYNSTOCK, De viribus liberi arbitrii humani.

1648: T 404 (44) - Theodorus BROUWER, De ecclesiae visibilis natura et notis.

1648: T 405 (43) - Theodorus BROUWER, De ecclesiae verae natura et notis.

Plaats van publicatie: UTRECHT <jaren van publicatie 1642-1648> Praeses/ Prof.: Gisbertus VOETIUS (1589-1676):

1646: V 294 (05) - Theodorus de GROEN, De templis, pars secunda.

1643: V 295 (04) - Dominicus BLAESIUS, De libertate conscientiae.

1648: V 296 (14) - Christophorus SUREDONCIUS, De episcopatu.

* Hs. - aantekening: "Mányoki István Uramnak".

1644: V 297 (11) - Stephanus le MOYNE, De potestate et politia, pars tertia. - STCN.

1644: V 298 (12) - Nicolaus OOSTDYCK, De potestate et politia, pars quarta.

1645: V 299 (13) - Paulus COLONIUS, De potestate et politia ... pars quinta.

1642: V 300 (06) - Lambertus van den WATERLAET, De pseudoprecationibus pars altera.

1644: V 301 (08) - Franciscus ROOSBECIUS, De ecclesia visibili, pars prima.

* Hs. - aantekening: "Mány[oki] ...".

1644: V 302 (09) - Joannes ab ISENHOUT, De ecclesia visibili, pars secunda.

1644: V 303 (10) - Joannes KRUYF, De ecclesia visibili, pars tertia.

1643: V 304 (03) - Adrianus MUNNINX, De excelsis mundi, quinta. - STCN.

1648: V $305(16)=R M K$ III.1711. - Petrus BACCA SZATTMARI.

1647: V $306(25)=R M K$ III.1690. - Petrus KALNAI.

1648: V 307 (33) - Isaacus RAAP, Problemata duo.

1647: V $308(07)=R M K$ III.6280. - Nicolaus Sz. ILLYE-FALVI.

1647: V 309 (67) = RMK III.1691. - Michael TOPHAEUS.

* Hs. - aantekening: "D[omi]no et Fratri Steph. Manyoki".

Plaats van publicatie: GRONINGEN < jaar van publicatie 1646> Praeses/ Prof.: Abdias WIDMARUS (1591-1668):

1646: W 218 (27) - Albertus BIERUMA, De Evangelio in genere. - STCN.

Noten

1 Zie hier vooral: Postma, 'Peregrinatio librorum.'

2 Ook waren ze verplicht om een aantal boeken mee te nemen voor de bibliotheek van hun eigen Hongaarse Alma Mater (als bijv. het Collegium in Debrecen, Sárospatak, Pápa, Kolozsvár, Marosvásárhely, Nagyenyed, Gyulafehérvár, etc.).

3 Zo kon bijv. de student Johannes / János N. Szepsi (afkomstig uit Sárospatak) zich financieel heel wat meer veroorloven dan zijn landgenoot Johannes / János Gele 
Debreceni (afkomstig uit Debrecen). Vgl. resp. Postma, 'Das Testament des verstorbenen ungarischen Studenten' en Postma, 'Warum Johannes Gele Debreceni bei Nacht und Nebel aus Franeker verschwunden ist.' Zie hier ook in het algemeen: Monok, 'The Readings of Hungarian Students.'

4 Over ons onderzoek naar Franeker academisch drukwerk in de bibliotheken en archieven aldaar berichtten we reeds eerder, zie: Postma, 'Franekeri akadémiai nyomtatványok nyomában. Három romániai tanulmányút élményei (1991-1993)', resp. Postma, 'Franekeri akadémiai nyomtatványok nyomában. Negyedik erdélyi tanulmányutam élményei (1994).'

5 Zie meer gedetailleerd hierover: Postma, 'Magyarok és a franekeri egyetemi oktatás', resp. Postma, 'De Hongaren en het onderwijs aan de Friese universiteit te Franeker.'

6 De plechtige opening vond plaats in de Grote of Martini Kerk te Franeker. Zie over de geschiedenis van de Franeker universiteit in het algemeen: Boeles, Frieslands Hoogeschool en het Rijks Athenaeum te Franeker en meer recent: Van Sluis, De Academie van Vriesland. Zie in dit verband ook: Postma, 'Latinország.'

7 Zie hierover met name: Postma, 'Franeckera, az igaz keresztyéneknek híres akadémiájuk benne.'

8 Dit aantal is gebaseerd op het Franeker Album Studiosorum. Uit andere bronnen weten we evenwel, dat het totale aantal Peregrini toch hoger moet zijn geweest.

9 Zoals bijv. Michaël Corvinus (afkomstig uit Körmöcbánya), die reeds eind februari 1624 Franeker bezocht. Zie: Postma, 'In tantis mundi tumultibus.'

10 De huidige signatuur luidt: <DD.VI.12>.

11 Zie de (huidige) rugtitel van deze bundel: Disputationes theologicae miscellaneae.

12 Zie over hem: $R M S z, 1: 514$ (s.v.). Mányoki was op 19 september 1640 student geworden aan het Collegium in Debrecen, zie: Borovszky, 'Debreczeni irók és tanárok', 458, resp. Thury, Series Studiosorum, 115.

13 Deze lange periode staat in de Hongaarse protestantse kerkgeschiedenis bekend als de tijd van de zgn. 'stille Contra-Reformatie'.

14 Op deze plaats dank ik Dr. Éva Schmelczer-Pohánka (destijds verbonden aan de UB Pécs) bijzonder hartelijk voor haar gedetailleerde informatie en verdere hulp. Domsics kreeg daartoe op 16 februari 1746 van de toenmalige bisschop van Pécs Sigismundus / Zsigmond Berényi - de schriftelijke opdracht. Zie hierover verder: Schmelczer-Pohánka, 'Amikor az 'inkvizítor' elbizonytalanodik.'

15 D.w.z. werken uit vroeger tijd, maar tegelijk ook eigentijdse geschriften. Daarnaast dus verboden boeken, als vermeld in de kerkelijke 'Index Librorum Prohibitorum'.

16 Klimo voorzag Mányoki’s convoluut van zijn fraaie - ingeplakte - "Ex libris". Zie verder over hem: Szinnyei, Magyar írók élete és munkái, 6:558-559.

17 PEK - TGYO Kt. 67046 = Ms 514, fol. 219-240. Zie voor een nadere beschrijving en inhoudelijke analyse van Domsics' boekenbezit: Schmelczer-Pohánka, 'Amikor az 'inkvizítor' elbizonytalanodik.'

18 De handgeschreven 'Catalogus Librorum Haeterodoxorum' is gedateerd: Pécs, 8 juli 1767.

19 Zie over Diestius en diens Hongaarse studenten in Deventer: Postma \& Eredics, 'Henricus Diestius (1595-1673) und seine ungarischen Studenten in Deventer'. Zie aldaar ook voor een nadere beschrijving van Szoboszlai's oefendisputatie (p. 81). Szoboszlai zou naderhand Diestius' boek Funda Davidis instructa quinque laevibus 
lapidibus (Daventriae 1646) in het Hongaars vertalen en in Debrecen - in 1648 laten verschijnen. Het boek is sterk gericht tegen de rooms-katholieke geloofsleer. Zie voor een bibliografische beschrijving: $R M K$ I.802.

20 ASt $G$, kol. 54: Stephanus Sart[orius] Mányoki. Hij liet zich daar op die dag inschrijven samen met Petrus Bacca Szatmári (van wie ook een Utrechtse oefendisputatie in Mányoki's convoluut is opgenomen: Volgnummer 16). Zie ook: Miklós, A groningeni egyetemen tanult magyarok névsora, 4, resp. Bozzay \& Ladányi, Magyarországi diákok holland egyetemeken, 1595-1918. N.B.: Enkele andere boeken die Mányoki tijdens zijn Peregrinatio verzameld had, troffen we in 2017 aan in de Teleki Téka te Marosvásárhely / Târgu Mures (RO), waaronder de eerste twee delen van Johannes Piscator, 'Commentarii in omnes libros Veteris Testamenti' (Herborn 1646); sign.: 〈Bf-165, I-II >.

21 Margitai was - evenals Mányoki zelf - student geweest aan het protestantse Collegium te Debrecen, zie: Thury, 'Series Studiosorum in Schola Debrecina Helveticae Confessionis, 1588-1792', 114 (6 april 1636). Voor én na Deventer studeerde hij in Franeker (zie: $A S t F$, Nr. 4363), daarna te Leiden en Utrecht (1649). Ook bezocht hij mogelijk Engeland (Londen), zie: Gömöri, Magyarországi diákok angol és skót egyetemeken, 1526-1789, 89 (Nr. 237). Zie verder: Szabó \& Tonk, Erdélyiek egyetemjárása a korai újkorban, 1521-1700, 208 (Nr. 2127), resp. Bozzay \& Ladányi, Magyarországi diákok holland egyetemeken, 1595-1918; RMSz, 1:516 (s.v.).

22 Van Slee, De Illustre School te Deventer, 1630-1878, 208 (6 oktober 1645). Zie ook: Segesváry, 'A devénteri athenaeumon tanult magyarok, 1644-1649', 507.

23 De uit Engeland afkomstige puriteinse theoloog Gulielmus Amesius (William Ames) telde talloze Peregrini onder zijn gehoor, en heeft zo een aanzienlijke invloed gehad in het Hongaarse achterland, cf. Auditorium, 86-103.

24 AStF, Nr. 4552: Stephanus S. Nanyoki (sic).

25 Stanislaus Hermannus (afkomstig uit Krakau) studeerde eerder (1645) aan het Gymnasium Illustre te Bremen, zie Achelis \& Börtzler, Die Matrikel des Gymnasium Illustre zu Bremen, 1610-1810, 82 (Nr. 32). In Franeker disputeerde hij niet alleen onder Johannes Coccejus, maar ook - zelfs meerdere keren - onder leiding van de hoogleraren Christianus Schotanus en Johannes Cloppenburg, zie: Auditorium, 52/1651.1; 8-10, resp. 56/1648.1; 6-7. Cf. resp. Postma, Studenci z Rzeczypospolitej we fryzyjskim uniwersytecie we Franeker en Postma, 'Frustula Polonica ac Lithuanica Franekerae impressa'.

26 Zie hier vooral ook: Auditorium, 56/1651.4abc (Cloppenburgs 'Compendiolum Socinianismi confutatum') en 56/1651.6 (Cloppenburgs weerlegging van de theologische opvattingen van de Engelse anti-trinitariër John Biddle: 'Vindiciae pro deitate Spiritus Sancti') - in beide gevallen een bundeling van oefendisputaties, verdedigd door - uitsluitend - Hongaarse Peregrini. Cf. Postma, 'Magyarok és a franekeri egyetemi oktatás', 118-122, resp. Postma, 'De Hongaren en het onderwijs aan de Friese universiteit te Franeker', 36-40. Cloppenburg stond als 'pater Hungarorum' hoog bij hen in aanzien. Ook bevatte zijn eigen bibliotheek ettelijke Hongaarse boeken, zie: Eredics, 'Johannes Cloppenburg professzor magyar könyvei'. Cf. Auditorium, 158-174.

27 Zie: Auditorium, 56/1646.5. De eerste oefendisputatie in deze lange reeks werd in 1646 verdedigd door de student Johannes Jacobus Desloch, 'Bipontino-Palatinus'. 
28 Zie: Auditorium, 56/1649.1. Dit eerste deel van zijn 'Anti-Smalcius' bevatte zijn weerlegging van de eerste twaalf hoofdstukken van Smalcius' werk, 'de munere Christi prophetico'. In 1652 verscheen te Franeker een nieuwe uitgave, nu gecompleteerd door een tweede deel 'Anti-Smalcius', zie: Auditorium, 56/1652.2.

29 Johannes Crispinus, 'Moravus' (zie: AStF, Nr. 4151), of elders 'O. Moravus' (vermoedelijk afkomstig uit Olomouc), was - volgens Mányoki’s aantekening in diens oefendisputatie - 'Alumnus' van het protestantse Collegium te Gyulafehérvár. Zie verder over hem: Engelbrecht, 'Die Bedeutung der friesischen Universität zu Franeker', 84, resp. Viskolcz, 'Johann Heinrich Bisterfeld és a gyulafehérvári tankönyvkiadás', 262, en Gömöri, Magyarországi diákok angol és skót egyetemeken, 1526-1789, 89 (Nr. 236); RMSz, 1:151 (s.v.).

30 Michael B. Pets-Varadi had zich samen met Nicolaus Margitai op 1 augustus 1645 te Franeker als student laten inschrijven: AStF, Nr. 4364, cf. Bozzay \& Ladányi, Magyarországi diákok holland egyetemeken, 1595-1918; RMSz, 1:614 (s.v.).

31 Szokolyai was - evenals Mányoki en Margitai - student geweest aan het protestantse Collegium te Debrecen, zie: Borovszky, 'Debreczeni irók és tanárok', 462, resp. Thury, 'Series Studiosorum in Schola Debrecina Helveticae Confessionis', 116 (20 mei 1642). Zie verder over hem: Zoványi \& Ladányi, Magyarországi Protestáns Egyháztörténeti Lexikon. Te Franeker liet hij zich - samen met Stephanus Peeri - als student inschrijven op 30 juni 1646: AStF, Nr. 4485, cf. Bozzay \& Ladányi, Magyarországi diákok holland egyetemeken, 1595-1918. Naderhand te Leiden zou hij nog ettelijke oefendisputaties verdedigen (zie o.a. beneden: noot 36), en verschillende theologische werken vanuit het Nederlands in het Hongaars vertalen. Zie voor dat laatste met name: Eredics, Ungarische Studenten und ihre Übersetzungen, 35-72; RMSz, 1:800 (s.v.).

32 Peeri was eerst (1640) student geweest aan het illustre protestantse Collegium te Sárospatak, zie: Hörcsik, A sárospataki Református Kollégium diákjai, 71. Samen met Szokolyai zou hij zich achtereenvolgens als student laten inschrijven te Franeker (zie: AStF, Nr. 4482), Groningen en Leiden, cf. Bozzay \& Ladányi, Magyarországi diákok holland egyetemeken, 1595-1918. Zie ook: Szabó \& Tonk, Erdélyiek egyetemjárása a korai újkorban, 263 (Nr. 2639); RMSz, 1:618 (s.v.).

33 "Gelida tempestate".

34 "in locis exoticis".

35 Zie - in het algemeen - over de gang van zaken bij het disputeren in Franeker, en de daarbij geldende regels: Postma, 'Magyarok és a franekeri egyetemi oktatás', 126134, resp. Postma, 'De Hongaren en het onderwijs aan de Friese universiteit te Franeker', 42-46.

36 AStL, kol. 375. Mányoki was bij zijn inschrijving te Leiden 26 jaar oud. N.B.: Hij zou in zijn convoluut maar liefst drie Leidse oefendisputaties van Szokolyai opnemen (Volgnummers 40, 41 en 61), en ook een Leidse disputatie van Peeri (Volgnummer 59). Peeri zou zich later nog inschrijven te Utrecht, zie: $A S t U$, kol. 17.

37 Handgeschreven aantekeningen in verschillende van deze Utrechtse exemplaren wijzen eveneens in die richting. Ook Peeri en Margitai zouden zich naderhand als student in Utrecht ophouden (zie boven).

38 Cf. Szinnyei, Magyar irók élete és munkái, 8: kol. 524: “1648. decz. 27-én Debreczenben tanár volt". 
39 Cf. Borovszky, 'Debreczeni irók és tanárok', 458, resp. Thury, 'Series Studiosorum in Schola Debrecina Helveticae Confessionis', 115 ("rector scholae Debrecinae 1649").

40 Erdélyi schreef zijn naam (en de datum) voorin het convoluut direct onder die van And[reas] S. Pathai, de vorige eigenaar, op de binnenzijde van de boekband. Hoe Mányoki's convoluut vele jaren later uiteindelijk in Pécs terecht is gekomen, blijft vooralsnog een open vraag.

41 Winswiler had ook eerder al (1623) onder Amesius gedisputeerd. Twee door hem verdedigde oefendisputaties vonden we terug in Amesius' Medulla theologica, dat oorspronkelijk in twee delen - als een bundeling van ettelijke oefendisputaties - te Franeker verscheen, zie: Pars secunda (1623), Nummer VIII en XX. Zie over Winswilers Hongaarse "commensalis" Paulus Puah Miskolczi: Zoványi \& Ladányi, Magyarországi Protestáns Egyháztörténeti Lexikon, resp. RMSz, 1:546 (s.v.).

42 Johannes Thomas (afkomstig uit Willingen) was eerder - 1624 - student geweest in Herborn, zie: Zedler \& Sommer, Die Matrikel der Hohen Schule zu Herborn. In het najaar van 1626 kwam hij naar Franeker, wellicht in het gezelschap van Sebastianus Pfochenius, zie: AStF, Nummer 2344 en 2345. N.B.: Van Thomas' oefendisputatie onder Amesius vonden we tot nu toe geen enkel ander exemplaar.

\section{Bibliografie}

Achelis, Thomas Otto \& Börtzler, Adolf (eds.). 1968. Die Matrikel des Gymnasium Illustre zu Bremen, 1610-1810. [Bremisches Jahrbuch, 2.3.] Bremen: Carl Schünemann Verlag. - Afk.: Achelis \& Börtzler.

Album Studiosorum Academiae Groninganae. 1915. Groningen: J.B. Wolters. - Afk.: AStG.

Album Studiosorum Academiae Lugduno Batavae, 1575-1875. Accedunt nomina Curatorum et Professorum per eadem secula. 1875. Hagae Comitum: Martinus Nijhoff. - Afk.: AStL.

Album Studiosorum Academiae Rheno-Trajectinae, 1636-1886. Accedunt nomina Curatorum et Professorum per eadem secula. 1886. Ultrajecti: J.L. Beijers \& J. van Boekhoven. - Afk.: AStU.

Boeles, W.B.S. 1878-1889. Frieslands Hoogeschool en het Rijks Athenaeum te Franeker, 2 delen. Leeuwarden: H. Kuipers.

Borovszky, Samu. 1898. 'Debreczeni irók és tanárok, 1588-1700.' [Schrijvers en leraren uit Debrecen, 1588-1700.] Irodalomtörténeti Közlemények [Budapest], 9: 448-465.

Borsa, Gedeon e.a. (eds.). 1990-1996. Régi Magyar Könyvtár, III. [Oude Hongaarse Bibliotheek, III.] K. Szabó - Á. Hellebrant (eds.). Pótlások, kiegészitések, javitások, [Toevoegingen en correcties.] 5 delen. Budapest: Országos Széchényi Könyvtár. - Afk.: RMKP. 
Bozzay, Réka \& Ladányi, Sándor (eds.). 2007. Magyarországi diákok holland egyetemeken, 1595-1918. [Hongaarse studenten aan Nederlandse universiteiten, 1595-1918.] [Magyarországi diákok egyetemjárása az újkorban, 15.] Budapest: Eötvös Loránd Tudományegyetem. - Afk.: Bozzay \& Ladányi.

Engelbrecht, Wilken. 2000. 'Die Bedeutung der friesischen Universität zu Franeker für die tschechischen Exulanten nach der Schlacht am Weißen Berg.' Philologia Frisica Anno 1999. Ljouwert: Fryske Akademy, 57-87.

Eredics, Péter. 2001. 'Johannes Cloppenburg professzor magyar könyvei.' [De Hongaarse boeken van professor Johannes Cloppenburg.] Magyar Könyvszemle [Budapest], 117.1: 112-117.

Eredics, Péter. 2008. Ungarische Studenten und ihre Übersetzungen aus dem Niederländischen ins Ungarische in der Frühen Neuzeit. [Debrecener Studien zur Literatur, 14.] Frankfurt am Main, etc.: Peter Lang Verlag.

Fockema Andreae, S. J. \& Meijer, Th. J. (eds.). [1968]. Album Studiosorum Academiae Franekerensis, 1585-1811; 1816-1844. Deel 1: Naamlijst der studenten. Franeker: T. Wever. - Afk.: AStF (samen met het desbetreffende Volgnummer).

Gömöri, György (ed.). 2005. Magyarországi diákok angol és skót egyetemeken, 1526-1789. [Hungarian Students in England and Scotland, 1526-1789.] [Magyarországi diákok egyetemjárása az újkorban, 14.] Budapest: Eötvös Loránd Tudományegyetem.

Hörcsik, Richárd (ed.). 1998. A sárospataki Református Kollégium diákjai, 1617-1777. [De studenten van het Gereformeerde Collegium van Sárospatak, 1617-1777.] Sárospatak: Sárospataki Református Kollégium.

Miklós, Ödön. 1917. A groningeni egyetemen tanult magyarok névsora. [De naamlijst van de Hongaarse studenten in Groningen.] Pápa: Főiskolai Könyvnyomda.

Monok, István. 2015. 'The Readings of Hungarian Students during their Studies in the Netherlands in the Early Modern Period.' Gosker, Margriet \& Monok, István (eds.). Peregrinus sum. Studies in History of Hungarian-Dutch Cultural Relations in Honour of Ferenc Postma on the Occasion of his 70th Birthday. Budapest / Amsterdam: s.n., 93120.

Móró, Mária Anna (ed.). 2001. A Pécsi Egyetemi Könyvtárban örzött Klimo-könyvtár katalógusa. [Catalogus van de Klimo-bibliotheek in 
de Universiteitsbibliotheek te Pécs.] Deel I: A könyvek szerzői betürendes katalógusa. Budapest: Tarsoly Kiadó.

Postma, F[erenc] \& Sluis, J. van (ed.). 1995. Auditorium Academiae Franekerensis. Bibliographie der Reden, Disputationen und Gelegenheitsdruckwerke der Universität und des Athenäums in Franeker, 1585-1843. [Minsken en Boeken, 23.] Leeuwarden / Ljouwert: Fryske Akademy. - Afk.: Auditorium.

Postma, Ferenc. 1997. 'Franeckera, az igaz keresztyéneknek híres akadémiájuk benne [oder die Frage, warum nach der Zerstörung von Heidelberg (September 1622) die sogenannte Peregrinatio hungarica sich von Heidelberg nach Franeker verlegt hat].' [Franeker, dat de beroemde academie der ware christenen herbergt.] Balázs, Mihály e.a. (ed.). Müvelödési törekvések a korai újkorban. Tanulmányok Keserü Bálint tiszteletére. [Adattár, 35.] Szeged: József Attila Tudományegyetem, 487-495.

Postma, Ferenc. 1998. 'Franekeri akadémiai nyomtatványok nyomában. Három romániai tanulmányút élményei (1991-1993).’ [Op zoek naar Franeker academisch drukwerk. Impressies van een drietal studiereizen naar Roemenië (1991-1993).] Könyv és Könyvtár [KLTE/ DE, Debrecen], 20: 113-133.

Postma, Ferenc. 1999. 'Franekeri akadémiai nyomtatványok nyomában. Negyedik erdélyi tanulmányutam élményei (1994).' [Op zoek naar Franeker academisch drukwerk. Enkele impressies van mijn vierde studiereis naar Zevenburgen (1994).] Könyv és Könyvtár [KLTE/ DE, Debrecen], 21: 233-256.

Postma, Ferenc. 2006. 'Peregrinatio librorum. Der große Auszug von Büchern aus den Niederlanden nach Ungarn und Siebenbürgen seit der Gründung der nordniederländischen Universitäten.' Hollander, August den; Monok, István \& Postma, Ferenc (eds.). Studiosorum et librorum peregrinatio. - Hungarian-Dutch Cultural Relations in the 17th and 18th Century. Amsterdam/Budapest: Universiteit van Amsterdam / Országos Széchényi Könyvtár, 15-18.

Postma, Ferenc. 2010. 'Magyarok és a franekeri egyetemi oktatás.' [De Hongaren en het onderwijs aan de universiteit in Franeker.] Pusztai, Gábor \& Bozzay Réka (eds.). Debrecentöl Amszterdamig. Magyarország és Németalföld kapcsolata. Debrecen: Printart-Press, 113-156.

Postma, Ferenc \& Eredics, Péter. 2010. 'Henricus Diestius (1595-1673) und seine ungarischen Studenten in Deventer. Ein kleiner Beitrag zu seiner Rezeptionsgeschichte und Bibliographie.' Stemler, Ágnes \& 
Varga, Bernadett (eds.). Mint az gyümölczös és termett szölöveszszö... Tanulmányok P. Vásárhelyi Judit tiszteletére. Budapest: Országos Széchényi Könyvtár/ Balassi Kiadó, 71-89.

Postma, Ferenc. 2012. 'In tantis mundi tumultibus ... A Franekerben tanult magyarok legkorábbi emlékkönyvi bejegyzései: Öt inscriptió Michaël Corvinus Album Amicorumában (1624).' [In tantis mundi tumultibus ... De vroegste albuminscripties van Hongaarse studenten uit Franeker: Vijf inscripties in het Album Amicorum van Michaël Corvinus (1624).] Református Szemle [Cluj-Napoca / Kolozsvár], 105.6: 589-598.

[* In het Nederlands verschenen in: Acta Neerlandica. Bijdragen tot de Neerlandistiek [DE, Debrecen] 2012, 9: 97-113.]

Postma, Ferenc (ed.). 2014. Studenci z Rzeczypospolitej we fryzyjskim uniwersytecie we Franeker. Spis nazwisk i bibliografia. [Studenten uit Polen en Litouwen aan de Friese universiteit in Franeker: Naamlijst en Bibliografie.] [Ksiazki bez Kantów.] Kraków: Collegium Columbinum.

Postma, Ferenc. 2015. 'De Hongaren en het onderwijs aan de Friese universiteit te Franeker.' Acta Neerlandica. Bijdragen tot de Neerlandistiek [DE, Debrecen], 10: 33-80.

Postma, Ferenc. 2016. 'Warum Johannes Gele Debreceni bei Nacht und Nebel aus Franeker verschwunden ist: Die Franeker Inventarliste seiner dort hinterlassenen Bücher und Güter (1661).' Nyerges, Judit; Verók, Attila \& Zvara, Edina (eds.). MONOKgraphia. Tanulmányok Monok István 60. születésnapjára. Budapest: Kossuth Kiadó, 574-585.

[* Eerder verschenen in: It Beaken 2015 [FA, Leeuwarden/Ljouwert], 77.3-4: 107-123.]

Postma, Ferenc. 2017a. 'Das Testament des verstorbenen ungarischen Studenten Johannes / János N. Szepsi (Franeker, den 28. April 1658) und die erfreuliche Entdeckung von etlichen Büchern aus seinem Nachlass.' Sárospataki Füzetek [SRTA, Sárospatak], 21.2: 145-166.

[* Met aanvullingen, in: It Beaken 2018 [FA, Leeuwarden/Ljouwert], 80.1-2: 22-58.]

Postma, Ferenc. 2017b. 'Frustula Polonica ac Lithuanica Franekerae impressa. Ein kleiner Beitrag aus Franeker zu der Polnischen Nationalen Bibliographie.' Nastulczyk, Tomasz e.a. (eds.). Nihil sine litteris. Scripta in honorem Professoris Venceslai Walecki. Kraków: Uniwersytet Jagiellonski, 587-600. 
Postma, Ferenc. 2019. 'Latinország. Különleges kiállítás az egykori Franekeri Egyetemröl.' [Land van Latijn. Een bijzondere tentoonstelling over de voormalige Universiteit Franeker.] Gerundium. Egyetemtörténeti Közlemények [DE, Debrecen], 10.1: 145-150. [* Ook verschenen in: Református Szemle 2019 [Cluj-Napoca/Kolozsvár], 112.3: 330-335.]

[* In het Nederlands verschenen in: Acta Neerlandica. Bijdragen tot de Neerlandistiek 2019 [DE, Debrecen], 15: 269-274.]

Schmelczer-Pohánka, Éva. 2019. 'Amikor az 'inkvizitor' elbizonytalanodik. A tiltott müveket olvasó Domsics Mátyás pécsi kanonok könyvgyüjteménye a 18. század derekán.' [Als de inquisiteur twijfelt. De achttiende-eeuwse bibliotheek van de Pécser kanunnik Mátyás Domsics, die verboden werken las.] Borsy, Judit (ed.). Reformáció a DélDunántúlon. Pécs/Kaposvár/Szekszárd: Magyar Nemzeti Levéltár/ Baranya Megyei Levéltár etc., 423-444.

Segesváry, Lajos. 1937. 'A devénteri athenaeumon tanult magyarok, 1644-1649.' [Hongaarse studenten aan de Illustre School te Deventer.] Századok [Budapest], 71: 506-508.

Slee, J.C. van. 1916. De Illustre School te Deventer, 1630-1878. Hare geschiedenis, hoogleeraren en studenten, met bijvoeging van het Album Studiosorum. 's-Gravenhage: Martinus Nijhoff.

Sluis, Jacob van. 2015. De Academie van Vriesland. Geschiedenis van de Academie en het Athenaeum te Franeker, 1585-1843. Gorredijk: Bornmeer.

Szabó, Károly \& Hellebrant, Árpád (eds.). 1879-1898. Régi Magyar Könyvtár, [Oude Hongaarse Bibliotheek.] 3 delen. Budapest: M. Tud. Akadémia Könyvkiadó. - Afk.: RMK.

Szabó, Miklós \& Tonk, Sándor (eds.). 1992. Erdélyiek egyetemjárása a korai újkorban, 1521-1700. [Studenten uit Zevenburgen aan buitenlandse universiteiten in de vroegmoderne tijd, 1521-1700.] [Fontes rerum scholasticarum, 4.] Szeged: József Attila Tudományegyetem. Afk.: Szabó \& Tonk.

Szinnyei, József (ed.). 1891-1914; Reprint 1980-1981. Magyar írók élete és munkái. [Leven en werk van Hongaarse schrijvers.], 14 delen. Budapest: Hornyánszky Kiadó. - Afk.: Szinnyei.

Thury, Etele. 1908. 'Series Studiosorum in Schola Debrecina Helveticae Confessionis, 1588-1792. / A debreczeni Református Főiskola tanulók névsora, 1588-1792.' Thury, Etele (ed.). Iskolatörténeti Adattár. Deel 2. Pápa: Főiskolai Könyvnyomda, 96-466. 
Viskolcz, Noémi. 2002. 'Johann Heinrich Bisterfeld és a gyulafehérvári tankönyvkiadás a XVII. században.' [Johann Heinrich Bisterfeld en het uitgeven van schoolboeken in Gyulafehérvár in de $17^{\text {de }}$ eeuw.] Magyar Könyvszemle [Budapest], 118.3: 249-271.

Wix, Györgyné \& Vásárhelyi, Judit P. (eds.). 200[8]. Régi Magyarországi Szerzök.[Oude Hongaarse schrijvers.] Deel 1: A kezdetektöl 1700ig. Budapest: Országos Széchényi Könyvtár. - Afk.: RMSz.

Zedler, Gottfried \& Sommer, Hans (eds.). 1908. Die Matrikel der Hohen Schule und des Paedagogiums zu Herborn. [Veröffentlichungen der historischen Kommission für Nassau, 5.] Wiesbaden: J.F. Bergmann Verlag. - Afk.: Zedler \& Sommer.

Zoványi, Jenő \& Ladányi, Sándor (eds.). 1977. Magyarországi Protestáns Egyháztörténeti Lexikon. [Kerkhistorisch lexicon van het Hongaarse Protestantisme.] 3. Kiadás. Budapest: A magyarországi Református Egyház zsinati irodájának sajtóosztálya. - Afk.: Zoványi \& Ladányi.

\section{Archivalia}

PEK TGYO Kt. $67046=$ Ms 514.

[* Pécsi Tudományegyetem Egyetemi Könyvtár és Tudásközpont, Történeti Gyüjtemények Osztálya, Kézirattár.]

N.B.

* Een Hongaarse vertaling van dit artikel, van de hand van Dr. Péter Eredics, verscheen in: Méreg, Martin; Molnár, Dávid \& SchmelczerPohánka, Éva (eds.). 2019. A hazának hü őre és oszlopa. Szepesy Ignác pécsi püspök emlékezete. [A Pécsi Egyetemi Könyvtár kiadványai, 17.] Pécs: Pécsi Tudományegyetem, 159-178.

* István Mányoki's bundel 'Disputationes theologicae' kwam ook uitgebreid aan de orde op een studiedag van de Dr. P.A. Tiele-Stichting, in de Koninklijke Bibliotheek te Den Haag, op vrijdag 12 april 2019, tijdens ons referaat: "Wat heeft een Nederlandse boekhistoricus nu te zoeken in Hongarije?" Zie: Nieuwsbrief Dr. P.A. Tiele-Stichting [Samenwerkingsverband voor Boekwetenschap in Nederland], Nr. 33 (november 2019). 